\title{
Exploration of the Non-normal Students' Attitude to Taking Part in the Teacher Qualification Examination in China
}

\author{
Lu Gong \\ Southwest University, Chongqing 400715, China; \\ Kaili University, Kaili, Guizhou 556000, China
}

\begin{abstract}
As the teacher qualification examination has been extensively spread in China in recent years, a "national examination fever" is rising among non-normal students. A large number of non-normal college students have obtained the teacher certification by taking the qualification exam. It is found that there are all kinds of attitudes to the students' participating in this exam. Firstly, they once had to choose a non-normal major on account of different reasons, although they expect to be teachers. Secondly, they hold a blind attitude that all their friends take part in it. Thirdly, it is a practical way to have a job choice after graduation. Therefore, we have a responsibility to remind the students to treat the examination rationally, because it can't ensure them the capabilities required for a qualified teacher even if they have passed three or four subjects. Meanwhile, those who participate in the exam only plan to increase the possibility of getting employed instead of genuine enthusiasm for education can hardly enjoy satisfaction and happiness. Therefore, the non-normal students should recognize and understand the true purpose of the examination and make a rational career planning. At the same time, the government needs to improve the teacher qualification examination system.
\end{abstract}

Index Terms - teacher qualification examination, non-normal student, attitude

\section{INTRODUCTION}

For a long time, the construction of teachers' team is carried out in relatively conservative way and teacher qualification is lifetime. The normal students of all majors at university are "quasi-teachers", and the teacher certification is also practiced for life. They usually passed the test of mandarin and calligraphy at university, and then applied for a certificate on the designated website. They could obtain the teacher qualification of the corresponding discipline at university. It is required for a student to get the certification before becoming a formal teacher. At the same time, it is difficult for many excellent students who want to be a teacher to get the certification. Therefore, the traditional system of applying for teacher certification makes the unemployed teachers avoid the competition pressure because of the excellent welfare offered by the "iron rice bowl (a secure job)". In order to attract more talented people, China is enhancing the construction of teachers' team, to stimulate the vitality of the teachers' team and improve the quality of education. China is learning from the successful experience of the United States and Japan by reforming the national primary and secondary school teacher qualification examinations to absorb more talents into teachers' team. In Japan there are several types of professional development programs developed by the government: leadership development; internships for becoming public school teachers with a supervised, reflective induction into teaching (Shimahara, 2002). Since 2011, China has gradually carried out the national primary and secondary school teacher qualification examination in the range of the whole country, and to further standardize the requirements for teachers.

The challenges of getting a certification can be as basic as determining a regulatory body capable of training teachers and providing time and capitals to complete the training. "Certification is the process of deciding that an individual meets the minimum requirements of competence in a profession. Licensing is the legal process of permitting a person to practice a trade or profession once he or she has met certification standards" (Cronin, 1983, p.171)). "The establishment of the teachers' qualification examination system in China has experienced three periods: the first period is from 1978 to 1993, in 'Decision on Reform of the Education System of the Central Committee of the Communist Party of China' as a guide to establish the system of primary and secondary school teachers in the inspection of certification. The second period is from 1993 to 2009, 'Chinese Education Reform and Development Compendium' as a guide to build the teachers' qualification system. Teacher qualification examination is to measure the quality of teachers and social workers. The third period is from 2009 to present, 'National Long-term Education Reform and Development Plan Outline (2010-2020)' to guide China to gradually establish a teacher qualification examination system." (Chen, 2015, p.98). The examination is held twice a year, with the written examination in March and November, and the interview in May and December if the written test is passed. Teacher qualification exam was first held in November 2011 in Hubei and Zhejiang province. The Ministry of Education announced that since the students of 2015 class will no longer be directly recognized as teachers' qualification when graduation. The "life-long" mode of teacher qualification was cancelled at the same time, and the registration must be performed every five years. 
The examination of teacher certification is divided into two parts: written examination and interview. The written examination subjects of teacher certification for kindergarten teachers include "comprehensive quality" and "teaching knowledge and ability". The written examination subjects for primary school teachers are "comprehensive quality" and "education and teaching knowledge and ability". The written examination subjects for general senior middle school teachers and secondary vocational school are "comprehensive quality", "educational knowledge and ability", "subject knowledge and teaching ability". The written examination subjects for secondary vocational school teachers are "professional knowledge and teaching ability". The exams are temporarily propelled and organized by the provinces (autonomous region, municipality). As for the interview examination subjects, the interview for kindergarten teachers is not divided into subjects; the interview for primary school teachers is divided into 8 subjects: Chinese, mathematics, English, society, science, music, sports and art; the interview subjects and written examination subjects for middle school teachers (discipline knowledge and teaching ability) are consistent, a total of 13 disciplines, i.e. Chinese, mathematics, English, physics, chemistry, biology, politics, history, geography, sports and health, music, art and information technology. The interview examination is conducted in the form of trial and structured interview. After passing the written examination and interview, the participants can get the certificate of achievement, and finally apply for the teacher's qualification certificate on the official website.

\section{Literature REVIEW ON TEACHER QUALIFICATION EXAMINATION}

A total of 2252 results were retrieved from CNKI through entering the term of "teacher qualification examination". The earliest research started in 1978. From 1998, the number of annual research has been continuously increasing, with 295 research papers published in 2016. Through analyzing the authoritative and academic papers in recent years, it is found that these papers are focused on several main aspects of teacher qualification examination.

First of all, it is about the implementation of teacher qualification examination system. "In order to effectively implement the policy of teacher qualification examination, we need to establish and improve the discipline system of teaching education, the professional education system of the applicants for teacher qualification examination and the professional quality guarantee system for teachers' training. Further clarification is required for the relationship between teacher qualification examination and teacher education, the relationship between teacher qualification examination and teacher education curriculum "(Zhu, Yuan, 2016, p.105). Some people think that the current qualification examination system of primary and secondary school teachers has some conflicts with the curriculum standards in terms of teacher training and examination content, so it is necessary to reform the system. The government should take some measures, for example, grant some normal universities the autonomy of conducting teacher qualification examination, enhance the compulsory education of teachers, increase the difficulty of the exam, perfect the examination conditions, establish a strict examination system of teaching practice and establish the "tutorial system", to promote the effective implementation of teacher qualification examination (Lin, Liu , 2015).

Secondly, it is about the reflection on the reform of teacher qualification examination. "Examination standards, examination contents and examination methods are three important issues in the reform of teacher qualification examination for primary and secondary school teachers. The pilot reform has realized the transformation of national examination standard from scratch, and the examination content from emphasizing the subject curriculum system to the comprehensive pattern of "written examination + interview"'(Feng, 2016,p.107).

Thirdly, it is about the influence of teacher qualification examination on university curriculum. The national examination system will lead to the adjustment of university curriculum, the change of training mode and the decrease of primary education source. Such adjustment and change are not favorable for cultivating high-quality primary school teachers. In order to reduce or mitigate such influence, the national unified standards should be formulated based on the reform of the subjects, contents and forms of teacher qualification examination for primary school teachers, or professional graduates can directly obtain teacher qualification certificate for primary school (Li, Wu, 2016). Some people believe that the teacher qualification examination system should be reformed first in the aspect of policy, so as to promote the development of basic education and improve teachers' professional capabilities, implement the teacher education reform and solve the practical problems in implementing the teacher education curriculum. For example, in the construction of teacher education system, it was proposed to streamline the courses and to improve the proportion of specialized education courses ( $\mathrm{Hu}, 2017)$.

Fourthly, it is about the case study. Based on the experience of teacher qualification examination and the experience of Hainan Normal University, the curriculum reform of teacher education and the coping strategies are analyzed in order to find a better way to improve the school teachers' quality. Liang Shan believed that higher normal colleges and universities should strengthen the kindergarten teachers' core competence in the professional curriculum together with the requirements of the national unified examination, strengthen the education of teachers' ethics, enrich the subjects of cultural literacy in general curriculum, pay attention to the educational effect of practical courses and highlight the practice in teachers' cultivation (Liang, 2014). However, only one study focusing on the attitude to teacher qualification examination was retrieved, saying that "The cognition and attitude of normal students to teacher qualification examination -- the investigation and analysis of H Normal University." (Liu, 2016, p.129). One of the reasons for conducting this study was that there are few studies on the attitude to students' participating in teacher qualification examination. 


\section{Non Normal StUdents' ATtITUde TO TEACHER QUALIFICATION EXAMINATION}

The author teaches at the training class for teacher qualification examination. A large number of investigations show that the students attending the examination mainly have these kinds of attitudes: Firstly, they really like the profession of teachers, but accidently chose other majors for some reason. Secondly, they want to try the exam because their friends are participating in it, which is a kind of blind attitude. Thirdly, they are pursuing for a job opportunity after graduation, which is more utilitarian.

\section{A. They Like the Teacher's Job}

Some non-normal students take part in the college entrance examination because they had not clearly determined their career goals, or were advised by others to choose a major other than teachers. When they went to university, they gradually realized their strengths and weaknesses and knew what jobs they were suitable for. So they took part in the teacher qualification examination, hoping to engage in their favorite career through this way. This is also the greatest advantage of the reform of teacher qualification examination, which can provide a chance for the non-normal students who are enthusiastic for teachers' profession.

\section{B. A blind Attitude}

Nowadays, some college students are confused about their future. Some of them may be influenced by their parents' thoughts on their career, so that they still can't think independently what they want after adulthood. But parents cannot provide more details for adults, so this group of students follows their classmates and do what others do, totally in a meaningless state of blind obedience. They do not understand the meaning of their participating in the teacher qualification examination, and do not know whether they like the profession or not.

\section{A Utilitarian Attitude}

Another group of non-normal students hold a utilitarian attitude to taking part in the teacher qualification examination. They are very clear about their feelings for teachers. Although they do not like the profession, they are forced to take a teacher qualification examination for a career choice after graduation. This is a utilitarian thought. These students are very opinionated and have a good foresight for the future. On the one hand, they will learn the current major, and strive to take the teacher's profession after graduation. In this way, once they are unable to undertake their professional work, they can also take part in the recruitment of teachers. In particular, the employment rate of the special post teachers is more than $90 \%$. Therefore, a teacher's qualification certificate can at least provide a job opportunity after graduation. The special post teacher policy was released to promote the compulsory education in the rural areas of the western region in 2006. The government tries to guide and encourage college graduates to engage in compulsory education in these areas. This initiative can supplement the teachers' team in rural schools, and gradually solve the problems of inadequate teacher resources and unreasonable structure in rural schools, so as to improve the overall quality of rural teachers and promote the balanced development of overall education.

\section{Teacher Qualification And Teachers' Professional DeVelopment}

Because the national unified examination will gradually be required for all teachers, the relevant training institutions have mushroomed. So, we have the reflection: why so many non-normal students suddenly turn to education field? Education is a big plan, and teacher is the base. Teaching and educating students are the lofty duty of teachers. At the same time, the key to the reform of education is also the teachers. As a result, a large number of non-normal students will become teachers in the future and they desire to obtain the teacher qualification. But some aspects still need to be improved at present, for example, the existing system is not conducive to the professional development of teachers. The professional development of teachers means that in the occupation career, through special training and lifelong learning, teachers gradually acquire professional knowledge and skills in professional education and constantly improve their teaching quality, thus becoming the professionals in education field. It contains two meanings. On one hand, it refers to a professional teacher who has grown up from a novice through professional training. On the other hand, it also refers to the process of teachers' progress from non-professional state to professional state.

\section{A. Getting Teacher Qualification Is Easy}

Firstly, the requirement for degree is not strict. High school teachers require a bachelor degree or above, while kindergarten and primary school teachers only require college degree or above. The enrollment expansion of universities has lowered the scores for college entrance. The minimum score for college entrance was 220 in 2014 . Only one-third of the total score of college entrance examination is required to apply for teacher qualification exam! These people's knowledge reserve and teaching ability cannot be guaranteed. Kindergarten and primary school are the foundation of life. At this stage, the quality of education directly affects the development of follow-up education. More attention should be paid to the acquisition of teacher qualification rather than lower the standard.

Secondly, the examination is easy. Although the subjects of written examination like "education" "psychology", "comprehensive quality", "teaching knowledge and ability" and "knowledge base education" becomes more difficult, they are still too easy compared with other professional examinations such as doctors and lawyers, etc. Therefore, a 
large number of non-normal students choose to take part in the teacher qualification examination, while it is impossible for a large number of students to pass the judicial examination. For example, the subject of "Comprehensive Quality" is too easy and rigid: in the past few years, it is found that there is a pattern can be followed in the material and writing. The material analysis of preschool teachers only examines two aspects of professional knowledge and professional ethics. Generally, it is a material analysis of a teacher's education and teaching behavior. The former answers come from the view of educational department, the view of the students and the view of teachers. The latter is analyzed one by one from the six aspects of the professional ethics. In the way of "knowledge + material", the knowledge by rote learning is hard to memorize, and it can be counted as correct without comprehensive understanding. At the same time, "Since the first examination in the second half of 2011, there have been totally 816561 people attending the written examination and 816561 people taking part in the interview, and 216794 people have passed the two examinations."(Chen, 2015,p.98). The success rate is $69.98 \%$ for the interview. How can the non-normal students really be qualified for the job of teachers?

\section{B. The Realization of Teachers' Professional Development Is Difficult}

"The new curriculum reform requires teachers to change the traditional education idea and possess good teaching skills and research ability." (Lu, 2006,p.71-76) Enthusiasm for one's profession is the foundation of teachers' professional development. The examination fever of non-normal students at least proves that the majority of these students do not really want to be teachers and they also lack professional knowledge and skills training. Secondly, the corresponding professional knowledge and abilities are the basis for the professional development of teachers. Teacher qualification examination cannot guarantee the knowledge reserve and teaching ability of non-normal students. Compared with normal students, they lack the professional knowledge and skills training at the undergraduate level. China is now advocating innovative education and striving to achieve great progress in education. Innovative education can't be achieved without innovative teachers. Education and scientific research are the primary productive forces in improving education, and educational research is the main way for teachers' professional development. Educational research is a systematic exploration of educational phenomena and educational practice by teachers with a goal and in a planned scientific way. This requires that every teacher should preside or participate in studying the subject and take the problems encountered in the education and teaching as a research topic. It reveals the inherent law of education, and then promotes the innovation and development of education. And many non-normal students are lack of professional training and necessary knowledge reserves. It is difficult for them to meet the requirements for the new-era teachers. Therefore, it is difficult for non-normal students to achieve the teacher's professional development. Passing teacher qualification exam does not mean a qualified teacher.

\section{The Non-normal Students Should Rationally Treat Teacher Qualification Examination}

\section{A. Clarifying the Purpose of Test}

Many of the students participating in teacher qualification examination do not really understand their true thoughts. Maybe they are affected by other students or parents' wishes. The survey shows that most people want more choices when looking for a job. If they can't get the job associated with their major, at least they can participate in the teachers' special position examination with high-admission opportunity. We have suggestions for those who have no enthusiasm for education career and just want to get a job.

\section{B. Know Yourself Reasonably}

An ancient Greek philosopher said, "Man, know yourself!" In the traditional teaching, writing can be a Chinese teacher. The society's demand for teachers has been much higher. But the outcome of teacher qualification examination can't comprehensively examine the potential of one's professional development. A kindergarten survey found that compared with non-normal students, children prefer normal college students, because normal college students can sing and dance, while non-normal students can only teach children to sing and understand common things, etc. Their teaching method is very simple so that they work hard to compete for teaching. In addition, the schools under little competitive pressure always are in poor working conditions. So before deciding to participate in the teacher qualification exam, please ask yourself if it is suitable for you.

Teachers are different from other jobs. They are working on the future of human. Teachers must be noble and full of wisdom. On the shoulders of the teacher is the nation's future.

\section{Make Career Planning}

The life without career planning easily loses goals and goes with the flow. Nowadays, there are a lot of courses related to career planning in high school, designed for helping students reasonably choose their majors in college entrance exam. Before entering university to carry on the professional study, everyone should do a reasonable career planning, so as to enrich college life and get ready to find a good job after graduation. To become a teacher, non-normal students should do a good job in vocational planning, and strengthen their professional courses at the same time to prepare for becoming a qualified teacher. 


\section{CONCLUSIONS}

The system of teacher qualification examination is rapidly developing and constantly improving. Gratifying results are achieved, and some problems are also occurring.

It is so exciting for non-normal students to have the chance of applying for teacher qualification certificate. From now on, they have to start from scratch in the same position with normal students, which is not fair for normal college students. Non-normal students can do major-related work after graduation, and can also enter the field of education through teacher qualification examination. Students spending four years getting a teacher qualification certificate is not a privilege. How can several exams be compared with the four years of professional training? Or is it because the society does not have enough trust in the cultivation of normal students?

The quality of teachers cannot be reflected by several exams. High-quality teachers are the key to the success of curriculum reform. We can't pursue quantity and ignore the quality. We should increase the difficulty of teacher qualification examination, expand the scope of the examination, and select the potential students that are enthusiastic for being teachers. We can learn from the experience of the legal profession that, non-normal students can do the teaching training again after passing the teacher qualification examination. After possessing the required credits and teaching skills, non-normal students can also become a teacher.

The important role of an examination is the selection. Teacher qualification examination has the responsibility to select the best people to improve the teaching quality. Obtaining a teacher qualification certificate is the first step to become a teacher. We should build the goal of increasing the difficulty of the exam, to enhance the training of non-normal students. Non-normal students should treat teacher qualification examination and make career planning in a rational way so as to understand the true meanings of life.

\section{REFERENCES}

[1] Cronin. (1983). State Regulation of Teacher Preparation. In L.Shulman\&G.Sykes(Eds.), Handbook of Teaching and Policy(p171). New York: Longman.

[2] Chen shang-qiong. (2015). Review of Chinese Teacher Certification Examination System Curriculum. Journal of Curriculum, Teaching Material and Method, (4), 98.

[3] Feng Jiagen. (2016). Three Questions on the Reform and Development of Teachers' Certification Examination in Primary and Middle Schools in China. Journal of Curriculum, Teaching Material and Method, (2), 107.

[4] Hu Qian. (2017). Study on the Curriculum Setting and Implementation of Pre service Teacher Education under the Background of Teachers' Certification Examination. Unpublished MA dissertation. Fujian: Min Nan Normal University.

[5] Liang Shan. (2014). The Curriculum Reform Path of Preschool Education in Normal University under the Background of Teacher Certification Examination -- Taking Xuzhou Kindergarten Teachers College as an Example. Journal of Jiang Su Infant Education,(3),26-28.

[6] Lin Tianlun \& Liu Ronghua. (2015). Thinking on the Implementation of the Certification Examination System for Primary and Secondary School Teachers -- Based on the Perspective of the Curriculum Standards for Teachers' Education. Journal of Research in Educational Development,(24),42-46.

[7] Li Haoquan \& Wu Yongzhong. (2016). The National Unified Examination System of Primary and Middle School Teachers' Certification and the Development of Primary Education. Journal of Educational Science Research, (12), 68-72.

[8] Liu Zhe. (2016). The Cognition and Attitude of Normal Students on the Teacher Certification Examination-- Based on the Investigation and Analysis of H Normal University. Journal of Journal of Nanchang Normal University, (4), 129.

[9] Lu Naigui, (2006). Comparative Education Review. The International Perspective of Teacher Professional Development (p71-76). Beijing: Beijing normal university press.

[10] Shimahara. (2002). Teaching in Japan: A cultural Perspective. New York: Routledge Falmer.

[11] Zhu Xudong \& Yuan Li. (2016). The System Design of the Implementation of the Teacher Certification Examination Policy. Journal of Educational Research, (5),105.

Lu Gong was born in Gui Zhou Province, People's Republic of China in 1988. She is studying education in Southwest University for her doctor's degree. Her research focuses on minority education and Chinese language education. At the same time, she works at Kail Li University in Guizhou. 